\title{
INTANGIBLE HERITAGE TOURISM: THE NEPALESE DIASPORA IN MALAYSIA
}

\author{
Kavitha Subaramaniam 1 , Swagata Sinha Roy ${ }^{2}$ \& Devendra Kumar Budakoti ${ }^{3}$ \\ 1,2Universiti Tunku Abdul Rahman \\ ${ }^{3}$ Independent Consultant/Researcher \\ (kavitha@utar.edu.my, swagata@utar.edu.my, ghughuti@gmail.com)
}

\begin{abstract}
Who are you? Where are you from? How did you end up in Malaysia? These are the common questions that the Nepalese community here in Malaysia has had to respond to many a time. We cannot blame the naïve attitudes that our Malaysians possess but it is a matter of regret that most Malaysians from other ethnic groups are not aware of the Nepalese community here, simply because there has been no exposure to their presence. The intangible heritage of one's ethnicity and culture play a crucial role in pointing out one's origin, identity and existence. In the context of tourism, it is essential to sustain this minority group as it may arouse the interest of the Nepalese not only in their motherland but also around the globe. Tourists will be interested to learn about how the Nepali diaspora is able to preserve their unique traditions despite the influence of urbanisation and other culturalisations. The authors would apply the functionalist approach to discuss how the intangible tourism not only benefits the nation's economy but also functions to prevent the extinction of the Malaysian Nepalese customs. The research questions that are posed for this paper are as follows i) How do the Nepalese Malaysians sustain their intangible heritage? ii) What measures are this minority group taking to safeguard their tradition? and iii) In what way will the preservation be able to benefit the country and themselves? In-depth interviews with 15 informants will be conducted along with consensual audio-recording. Transcriptions of the interviews will analyse the thematic patterns coupled with peer checking to reduce bias for the data to be credible and trustworthy. The outcome of this research will be presented.
\end{abstract}

KEYWORDS: Intangible heritage tourism, Minority ethnic, Nepalese diaspora, Malaysia

\section{PURPOSE AND BACKGROUND}

The Nepalese society is a minority community (Low, 2016) who lives with other larger ethnic groups in this country. Their identity is 'shaken-up' as Malaysians cluster them with the 'Indian' ethnic groups. Yes, they are Hindus and are of South Asian descent (Kalaimuthu, 2008), but they do not come from the Indian sub-continent.

As such, this confusion had led to an identity crisis among the youth who have difficulties in differentiating themselves and their origins. Moreover, it had caused many of the age-old traditions to be under 'threat' of losing their intangible heritage. In the landscape of tourism, this situation can be taken advantage of by the relevant authorities in promoting this minority population to the 'outside world'.

It could generate income 'handsomely' for the nation, as tourists would find this Nepalese culture as sui generis where they are able to withstand the pressure of major cultures and the impact of modernization. Besides that, this diaspora collective will also be able to protect their traditions with the help of these authorities. It is a win-win situation for both the country's economy and the Nepalese values. 


\section{METHODOLOGY}

The qualitative technique (Creswell, 2007) was used to extract the essential outcomes for this research paper due to the holistic nature of the data collection processes involved. Moreover, due to the nature of the study the researchers applied dual method in sourcing the information of the Nepalese minority group.

First, the documentation approach. These materials are from the hardcopies and softcopies of major English and Malay language newspapers in the country. Data gathered from the National Archives and the National Library of Malaysia will was also used in the search and compilation of the intangible heritage of the Nepalese diaspora in Malaysia.

Second, for the interview sessions. 15 respondents were chosen for in-depth interviews. The participants' contacts were provided by the gatekeepers and this enabled the researchers to narrow down the samples using purposive sampling (Patton, 2002) in order to get hold of imperative testimonies of their culture. The interviews were done in two ways, the first being face-to-face and the other being through telephone conversations.

All the oral communications were audio recorded with the informants' consent with the qualifier that the information collected be used for academic purposes only. These recordings were transcribed by the researchers in a bid to analyse and examine the thematic patterns that emerged from the participants' inputs.

Further, peer checking was conducted to cross-check the interpretation of the transcripts to reduce bias. This was to make sure that the information collected was credible and trustworthy.

\section{FINDINGS}

\section{Sustaining an Intangible Heritage}

Most of us have come across the word heritage literally referring to culture, custom, tradition, ancestry et cetera. However, when the term intangible is added to heritage it brings a different significance especially from the viewpoint of tourism.

It delves into the 'ABSTRACT' heritage which cannot be seen or touched but can only be known through a person's action or behavior such as knowledge and practice. As such, this form of intangible culture will be a stumbling block for the Nepali community, a known minority group in Malaysia. The rituals and festivals must be passed on to the next generation or these practices will vanish into thin air especially if there are no documentation explaining the symbolic practices.

In other words, the transmission of the tradition can only be upheld by humans if they want to maintain their identity in the future. Of course, there would be recreation, modification and elimination in the cultural rituals according to the timeline and space. The Nepali diaspora had incorporated their cultural elements into the local norms by simplifying their major celebrations such as Tihar, Bhai Tika and Dussehra/Dashain (Muthiah, 2008) and adapting it to the country they are residing in.

The Hindus are only given public holidays by the states in Malaysia for Deepavali and Thaipusam representing the Tamil community as this group is the largest ethnic composition compared to other Indian ethnic groups. These celebrations have attracted local and international tourists as they do not need to go to India to experience it.

Due to this scenario, celebration such as Tihar that runs up to five days for the Nepalis is celebrated in a simple and moderate manner in their house or temple. Some of the employed Nepalis will apply for annual 
leave from work and school goers may be absent from school. In essence, this form of accommodation has been adopted into their livelihoods in order to sustain their intangible heritage.

\section{Safeguarding Tradition}

Traditions will fade if one does not take the necessary measures to sustain them specifically the intangible elements. Safeguarding them will become impossible as there will be demise of the elderly, and the customs will be forgotten if not taught to their offspring. Moreover, initiative needs to be taken collectively by the community to ensure that these values are imparted to the younger community members who will eventually become the 'torchbearers' of the traditions.

There are various heritages that are facing extinction in the 21 st century such as language, food and attire. For the Nepali folk, their mother tongue is losing its hold as the youth are articulate in the Malay lingo because they attend the national school where the medium of instruction is the Malay language.

English is the second language that is practiced at school. Due to this status quo, their fluency in these two languages is better in terms of written, speaking and reading. Habitually, their native language will take a back seat. Parents who are illiterate of their native tongue want their children to learn and it and will look for tutors who are proficient in the Nepali language.

Besides that, another intangible scope that brings excitement to everyone is food. Every type of cuisine has its symbolic meaning in a society. So too does food, the food traditionally consumed by Nepalis. During major festivals the main courses (Chandran, 2020) such as bread and chicken masala are served with aromatic side dishes comprising a cucumber salad and spicy potato. For dessert there is the appetizing milk ball soaked in sugar syrup and rice pudding.

However, due to the Malaysian flavor many of the cooking ingredients have been altered to suit the local palate. These traditional delicacies will not diminish over time but will be diversified in accordance to the novel techniques in the culinary arts as food is a necessity factor in our lives. In addition, attire plays a substantial role in projecting one's ethnic identity. It makes one feel a sense of belonging when we are wearing our traditional clothes and share the similarities.

The Nepalese classic male apparel is the Daura-Suruwal suit while the female is draped in Nepalese style saree. Nevertheless, many are embracing the resident country's traditional outfits as part of the dominant culture (referring to the Indians). The men still don in Daura-Suruwal as it is similar to the Indian traditional garb and the women adorn the saree but in the 'Indian' style. Due to the nature of the costume, the transition takes place effortlessly because there are no extreme adjustments to their garments.

\section{Benefitting Economy and Preserving Cultures}

Tourism is an industry that can generate revenue for any nation as long they can manifest the cultural uniqueness of communities. As all of us are aware, Malaysia is a country that is known for its multiethnic, multireligious and multicultural composition.

This has always fascinated the people around the world as to how a pluralistic society can co-exist peacefully despite the many differences. This curiosity had led tourists to 'fly in' to the country and to experience this diversity for themselves. The Nepali diaspora is one of the minority ethnic groups that is slowly fading because of the overpowering of the mainstream ethnic segments. Due to this situation, the community leaders are trying their best to perpetuate their community's culture by getting the parents to instill their cultural components in the everyday life of their children. 
However, it is easier said than done as many parents have gradually incorporated the Indian and other ethnic milieu practices into their own lives. They would be better off if the state and/or federal governments are able to assist in their community's initiative to preserve their heritages. It would be interesting to see such a 'tiny' cultural group become a pulling factor for the tourists if proper promotion is executed.

The Nepali community even has their own shrine named Kali Amman Temple. If they were to have a community hall, they could have open houses for their festivals, conduct Nepali cultural activities such as classes for language, spiritual events and rites, dances, cooking and craftmanship even for the tourists. It will be a 'triple bonus' where the heritage is being retained, and it has become a welcome source of income for this community and country.

\section{CONCLUSION}

Cultural sustenance is not something easy especially when it comes to intangible heritages. It is a practice that needs to be carried out by each family in the community. Safeguarding the tradition has no value if one does not follow the customs.

Of course, as we live in an era that makes us adapt to a new environment, many of our traits will be diluted to create a new culture. As the diaspora moves from one generation to another, there will be a vacuum in the original cultural heritage as many outside influences will be infused into the present culture. This happens everywhere and anywhere there are minority cultures that have left the motherland. The preservation of the Nepali culture can be done if they were to 'exploit' the circumstances by coordinating with the relevant authorities to obtain a settlement for their society.

By doing so, they would be able to attract travelers to witness their 'microscopic' unique culture. The functionalist paradigm examined the social order of this community of having stability in pursuing a common goal which is to maintain their identity with the consensus of the Nepali members. Hence, tourism will be able to improve the Malaysian economy, domestically and internationally and be in sync with conserving the intangible heritage of the Nepali diaspora in Malaysia.

\section{CONTRIBUTION/PRACTICAL IMPLICATIONS}

This research paper highlighted the challenges of the Nepali community's intangible heritages. They are facing difficulties in sustaining their minority culture due to their tiny population compared to the other ethnic groups. Per se if the ministry intervenes by helping to secure the traditions of Nepali diaspora, they could turn this situation into a tourism commodity. Intrinsically both parties will have a solution for this issue.

\section{REFERENCES}

Chandran, S. (2020, 14 November). How Malaysian Nepalese celebrate Tihar with scrumptious food. The Star. Retrieved 20 March 2021, from https:/www.thestar.com.my/food/food-news/2020/11/14/howmalaysian-nepalese-celebrate-tihar-with-scrumptious-food.

Creswell, J. W. (2007). Qualitative inquiry \& research design: Choosing among five approaches (2nd ed.). London: Sage Publications.

Low, K. E. Y. (2016). Migrant warriors and transnational lives: Constructing a Gurkha diaspora. Ethnic and Racial Studies, 39(5), 840-857. DOI: 10.1080/01419870.2015.1080377. 